\title{
Complex personality disorder in bulimia nervosa
}

\author{
Sarah L. Rowe ${ }^{\mathrm{a}, *}$, Jenny Jordan ${ }^{\mathrm{a}}$, Virginia V.W. McIntosh ${ }^{\mathrm{a}}$, Frances A. Carter ${ }^{\mathrm{a}}$, Chris Frampton $^{\mathrm{a}}$, \\ Cynthia M. Bulik ${ }^{\mathrm{b}}$, Peter R. Joyce ${ }^{\mathrm{a}}$ \\ ${ }^{\mathrm{a}}$ Department of Psychological Medicine, University of Otago, Christchurch, PO Box 4345, Christchurch, New Zealand \\ ${ }^{\mathrm{b}}$ Departments of Psychiatry and Nutrition, University of North Carolina at Chapel Hill, USA
}

\begin{abstract}
Objective: Recent research has suggested a move toward a dimensional system for the classification of personality disorders (PDs). Tyrer's dimensional model using severity as a form of categorizing PDs was used to compare eating disorder outcome in women with bulimia nervosa $(\mathrm{BN})$ over 3 years.

Method: One hundred thirty-four women with BN were divided into 4 groups based on PD severity: no PD ( $n=32)$, personality difficulty $(n=27)$, simple PD $(n=29)$, and complex PD $(n=46)$. Eating disorder symptoms and attitudes, general psychosocial functioning, and depressive symptoms were examined at pretreatment and at 1-year and 3-year follow-up (posttreatment).

Results: The complex PD group had greater Axis I comorbidity and psychopathology than the remaining 3 groups at pretreatment. At 1-year and 3-year follow-up, there were no differences in eating disorder outcome, general psychosocial functioning, and depressive symptoms across the 4 groups.

Conclusion: These results suggest that having an increased number of PDs comorbid with BN does not influence eating disorder outcome up to 3 years after treatment.

(C) 2010 Elsevier Inc. All rights reserved.
\end{abstract}

\section{Introduction}

The categorical classification of personality disorders (PDs) has been the subject of considerable debate for some years [1-3]. Limitations of the categorical model have been widely noted, and a number of authors have advocated dimensional models for the classification of PDs [4-6]. One dimensional approach proposed by Tyrer and colleagues $[7,8]$ uses severity as a means of categorizing PDs. In an attempt to reconcile the frequently overlapping PD diagnoses, this approach divides groups into a 4-point severity scale: no PD (does not meet criteria for actual or subthreshold PD), personality difficulty (meets subthreshold criteria for 1 or several PDs), simple PD (meets criteria for 1 or more PDs within the same PD cluster), and complex PD (meets criteria for 2 or more PDs across different clusters) [8]. This model of PD severity has been used to examine the impact on mental disability and outcome in substance use, mood, anxiety, and psychotic disorders $[9,10]$. However, to

\footnotetext{
* Corresponding author.

E-mail address: sarah.rowe@otago.ac.nz (S.L. Rowe).
}

our knowledge, Tyrer's dimensional classification of PD severity has not previously been used to assess the impact on outcome in an eating-disordered group.

The prevalence of PDs in bulimia nervosa (BN) is reported to range from $21 \%$ to $67 \%$ [11-13]. The comorbidity of BN and PDs has been found to negatively impact clinical symptoms such as general psychiatric functioning, interpersonal skills, and social functioning $[14,15]$. In recent years, research has attempted to address the complexities of treating comorbid eating disorders and PDs by adapting psychotherapies such as dialectical behavior therapy [16], cognitive behavioral therapy [17], and interpersonal psychotherapy [18] to attend to the combination of eating disorder symptoms and personality pathology [15]. Mixed findings exist on the impact of personality pathology on eating disorder treatment outcome, with some studies reporting greater binge eating severity [19] and more disturbed psychiatric symptoms posttreatment in those with personality pathology $[14,20]$. In contrast, other studies report that the presence of a PD did not predict outcome [21-23].

The use of Tyrer's dimensional personality classification attempts to address the issue of multiple personality 
diagnoses by considering severity in terms of both extent and breadth of personality dysfunction across personality clusters. The present study aims to evaluate the ability of Tyrer's dimensional approach to predict pathology and outcome in a sample of women with BN participating in a randomized controlled trial of cognitive behavior therapy [24]. This will be achieved by (1) comparing the pretreatment characteristics of women with $\mathrm{BN}$ among the dimensional personality groups and (2) examining the impact of PD severity on BN outcome at 1 and 3 years posttreatment.

\section{Materials and methods}

\subsection{Overview}

Women with $\mathrm{BN}$ were recruited for a randomized clinical trial with long-term follow-up. The trial evaluated the additive efficacy of exposure-based vs non-exposure-based behavioral treatments to a core of cognitive behavior therapy.

All participants received 8 sessions of cognitive therapy before being randomized to a further 8 sessions of 1 of 3 forms of behavioral therapy: $(a)$ exposure to prebinge cues with binge eating prevented, $(b)$ exposure to prepurge cues with purging prevented, or $(c)$ relaxation training. Further details of the study design and outcome, and 3-year followup data have been presented elsewhere [24,25].

\subsection{Participants}

Participants were 134 women, aged 17 to 45 years, with a current Diagnostic and Statistical Manual of Mental Disorders, Revised Third Edition diagnosis of BN. Of the 135 participants entering the study, one was excluded from the analyses because Axis II data were missing. Exclusion criteria were current anorexia nervosa, current obesity (body mass index $>30$ ), current severe major depression, current psychoactive substance use disorder, bipolar I disorder, schizophrenia, current severe medical illness or severe medical complications of BN, and current use of psychoactive medications.

\subsection{Procedure}

This study received ethical approval from the Southern Regional Health Authority (Canterbury) and the University of Canterbury Ethics Committee. Participants provided written informed consent.

\subsection{Pretreatment assessment}

Current and lifetime psychiatric disorders and PDs were assessed using the Structured Clinical Interview for Diagnostic and Statistical Manual of Mental Disorders, Revised Third Edition Patient Version and Personality Disorders Version [26]. These assessments were completed by nontreating psychiatrists and psychologists. Eating disorder symptoms such as binge eating and purging frequency were assessed using the Comprehensive Bulimia Severity Index
(CBSI) [27]. The CBSI is a clinician-rated instrument that used questions reflecting concepts from the Eating Disorders Examination [28] and was designed to measure the frequency and intensity of bulimic symptoms (including food restriction and body dissatisfaction) and general functioning (mood, anxiety, substance use, and social and occupational functioning). The treating clinician completed the 17-item Hamilton Depression Rating Scale (HDRS) [29] and the Global Assessment of Functioning Scale (GAF; APA, 1987). The GAF is a measure of general psychosocial functioning over the past week. Participants completed selfreport questionnaires including the Eating Disorder Inventory (EDI) [30].

\subsection{Follow-up assessment}

Participants were reassessed at 1 and 3 years after the end of treatment. Follow-up assessment consisted of reevaluating eating disorder diagnosis and readministering CBSI, HDRS, GAF, and EDI measures.

\subsection{Statistical analyses}

The Statistical Package for the Social Sciences (SPSS, Version 12; SPSS Inc, Chicago, IL) was used to analyze data. Participants were divided into 4 groups: (1) no PD (absent or minimal symptoms), (2) personality difficulty (subthreshold symptoms, ie, 1 symptom short of diagnosis), (3) simple PD (1 or more PDs met within the same PD cluster), and (4) complex PD (2 or more PDs from different clusters). The PD clusters were cluster A (paranoid, schizoid, schizotypal PDs), cluster B (antisocial, borderline, histrionic, narcissistic PDs), and cluster C (avoidant, dependent, obsessive-compulsive PDs). $\chi^{2}$ tests were conducted on dichotomous variables. Fisher exact and $\chi^{2}$ tests were used for post hoc pairwise testing. One-way analyses of variance (ANOVAs) were conducted to examine the impact of personality pathology on binge and purge frequency, eating attitudes (EDI drive for thinness, bulimia, and body dissatisfaction), depressive symptoms (HDRS), and psychosocial functioning (GAF). Repeated-measures ANOVA was used to assess differences among the 4 groups over 3 time points. To reduce the risk of type I error, we have opted for a more stringent statistical significance level of $P<.01$ for all statistical testing. In the few instances where follow-up data were missing, no attempt was made to estimate or impute these values.

\section{Results}

\subsection{Characteristics of personality groups at pretreatment}

The mean age of the sample was 26.1 years $(\mathrm{SD}=6.1)$, and 91\% were New Zealand European. The remaining ethnicities were as follows: 4.4\% Maori/European, 1.5\% Maori, 1.5\% Pacific Island/European, 0.7\% Asian, and 0.7\% "other." There were no significant differences among the groups in 


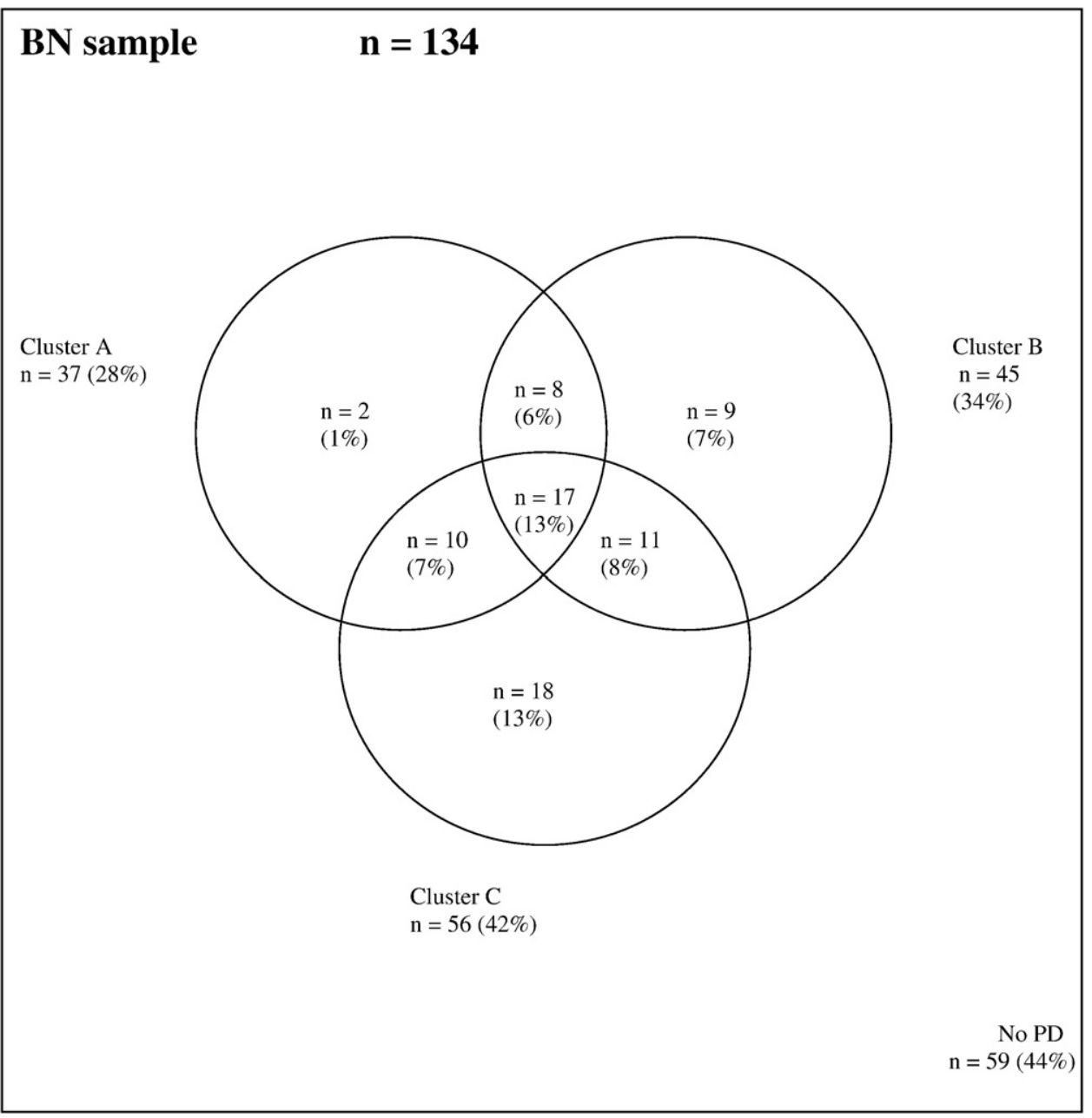

Fig. 1. Comorbidity across PD clusters in women with bulimia. Personality disorder clusters were as follows: cluster A (paranoid, schizoid, schizotypal PDs), cluster B (antisocial, borderline, histrionic, narcissistic PDs), and cluster C (avoidant, dependent, obsessive-compulsive PDs).

age of onset of $\mathrm{BN}$, duration, or lifetime diagnosis of anorexia nervosa. Diagnosis of an Axis II disorder was present in 56\% of the sample $(\mathrm{n}=75)$. Fig. 1 shows the overlap of Axis II diagnoses. Of the 75 participants with any PD, 29 had a simple PD (mainly cluster C), whereas 46 had a complex PD. Of those with a complex PD, 17 participants had PDs from all 3 clusters and 29 had combinations across 2 clusters.
Table 1 shows that those with complex PD had higher prevalence of any lifetime mood disorder than the no PD and personality difficulty groups and had higher prevalence of any lifetime anxiety disorder and any lifetime substance abuse/dependence than the other 3 groups. The simple PD group had significantly higher prevalence of lifetime mood disorder than the no PD group. Prevalence of any lifetime

Table 1

Axis I comorbidity of participants with BN stratified by the presence of no PD, personality difficulty, simple PD, and complex PD

\begin{tabular}{|c|c|c|c|c|c|c|c|c|c|c|c|}
\hline \multirow[t]{2}{*}{ Lifetime Axis I comorbidity } & \multicolumn{2}{|c|}{$\begin{array}{l}\text { No } P^{a} \\
(n=32)\end{array}$} & \multicolumn{2}{|c|}{$\begin{array}{c}\text { Personality } \\
\text { difficulty } \\
(\mathrm{n}=27) \\
\end{array}$} & \multicolumn{2}{|c|}{$\begin{array}{l}\text { Simple PD } \\
\quad(\mathrm{n}=29)\end{array}$} & \multicolumn{2}{|c|}{$\begin{array}{c}\text { Complex } \\
\text { PD }^{\mathrm{d}} \\
(\mathrm{n}=46)\end{array}$} & \multirow[t]{2}{*}{$\chi^{2}$} & \multirow[t]{2}{*}{$P$} & \multirow[t]{2}{*}{ Post hoc } \\
\hline & $\mathrm{n}$ & $\%$ & $\mathrm{n}$ & $\%$ & $\mathrm{n}$ & $\%$ & $\mathrm{n}$ & $\%$ & & & \\
\hline Any mood disorder & 13 & 41 & 15 & 56 & 22 & 76 & 40 & 87 & 21.0 & $<.001$ & $\begin{array}{l}\mathrm{a}<\mathrm{c}, \mathrm{d} \\
\mathrm{b}<\mathrm{d}\end{array}$ \\
\hline Any anxiety disorder & 6 & 19 & 14 & 52 & 12 & 41 & 36 & 78 & 28.1 & $<.001$ & $\begin{array}{l}\mathrm{a}<\mathrm{b} \\
\mathrm{a}, \mathrm{b}, \mathrm{c}<\mathrm{d}\end{array}$ \\
\hline Any substance abuse/dependence & 9 & 28 & 11 & 41 & 13 & 45 & 32 & 70 & 14.3 & .003 & $a, b, c<d$ \\
\hline
\end{tabular}

Post hoc statistics are $\chi^{2}$ or Fisher exact test. $\mathrm{a}=$ no PD group, $\mathrm{b}=$ personality difficulty group, $\mathrm{c}=$ simple PD group, $\mathrm{d}=$ complex PD group. The $P$ values in bold had a statistical significance level of $P<.01$. 
anxiety disorder was significantly higher in the personality difficulty group than in the no PD group.

At pretreatment, there were no significant differences in eating disorder symptoms such as binge eating and purging among the 4 groups (Table 2). However, those with simple PD or complex PD had higher scores on drive for thinness and body dissatisfaction subscales of the EDI.

Significant differences were found in depressive symptoms between no PD and complex PD and between personality difficulty and complex PD groups. The complex PD group had considerably higher levels of current depressive severity (HDRS) compared with the no PD and personality difficulty groups. At pretreatment, there was a small but statistically significant difference in GAF scores between the personality difficulty group and the complex PD group.

\subsection{Outcome at follow-up for the 4 groups}

Of the 134 women, follow-up data were available for 101 (75\%) women at 1-year follow-up and $112(84 \%)$ at 3-year follow-up. There were no difference in the rate of missing follow-up assessments among the groups at 1-year (no PD = $16 \%$, personality difficulty $=33 \%$, simple $\mathrm{PD}=24 \%$, complex PD $=28 \%)\left(\chi^{2}=2.7, P=.43\right)$ or 3 -year follow-up (no $\mathrm{PD}=13 \%$, personality difficulty $=19 \%$, simple $\mathrm{PD}=$ $17 \%$, complex PD $=8 \%)\left(\chi^{2}=0.5, P=.9\right)$. Ninety-two participants were assessed at all 3 time points; and complete data were available for all participants for the clinical interview, HDRS, and GAF. Self-report questionnaire (EDI) data were available for 76 out of the 92 participants at all 3 time points.

At 1-year follow-up, there were no significant differences among the 4 groups in binge or purge frequency, current diagnoses of $\mathrm{BN}$, anorexia nervosa, or eating disorder not otherwise specified. The overall remission rate from any eating disorder at this time point was $46 \%$ $(n=61)$. Differences among the groups at baseline for eating attitudes (drive for thinness and body dissatisfaction; Table 2), GAF, and current depressive symptoms (Table 3) were no longer present.

Similarly, at 3-year follow-up, there were no significant differences among the groups in binge and purge frequency, eating disorder diagnosis, or eating attitudes. At 3 years, the remission rate from any eating disorder was $58 \%(\mathrm{n}=77)$. The relapse rate at 3 years for the whole sample was $10 \%(\mathrm{n}=$ 9 ), and there were no significant differences across the groups (no $\mathrm{PD}=12 \%$, personality difficulty $=11 \%$, simple $\mathrm{PD}=$ $16 \%$, and complex PD $=4 \% ; \chi^{2}=9.4, P=.40$ ). Similarly, no significant differences were found in psychosocial functioning or depressive symptoms across the groups.

Further analyses were conducted using repeated-measures ANOVA to compare changes in outcome measures among the groups at pretreatment and at 1-year and 3-year follow-up. This revealed no significant difference in changes over time among groups in binge frequency (group $\times$ time

Table 2

Eating disorder outcome and EDI subscales at pretreatment and at 1-year and 3-year follow-up

\begin{tabular}{|c|c|c|c|c|c|c|c|c|c|c|c|}
\hline \multirow[t]{2}{*}{ Outcome measures } & \multicolumn{2}{|c|}{ No $P^{a}$} & \multicolumn{2}{|c|}{$\begin{array}{l}\text { Personality } \\
\text { difficulty }^{\mathrm{b}}\end{array}$} & \multicolumn{2}{|c|}{ Simple $\mathrm{PD}^{\mathrm{c}}$} & \multicolumn{2}{|c|}{ Complex PD $^{\mathrm{d}}$} & \multicolumn{3}{|c|}{ Statistics } \\
\hline & M & SE & M & SE & M & SE & M & SE & $F$ & $P$ & Post hoc \\
\hline \multicolumn{12}{|l|}{ Binge } \\
\hline Pretreatment $^{\mathrm{a}}$ & 11.6 & 1.7 & 12.0 & 2.6 & 9.1 & 1.6 & 10.0 & 11.7 & .46 & .71 & \\
\hline $1-y$ follow-up ${ }^{b}$ & 2.0 & 0.9 & 2.4 & 0.8 & 1.9 & 0.7 & 1.6 & 0.5 & .21 & .89 & \\
\hline $3-y$ follow-up ${ }^{c}$ & 3.6 & 1.3 & 2.7 & 1.4 & 2.3 & 4.5 & 0.4 & 0.1 & 2.4 & .08 & \\
\hline \multicolumn{12}{|l|}{ Purge } \\
\hline Pretreatment & 13.2 & 1.8 & 13.6 & 3.0 & 12.1 & 2.0 & 16.7 & 4.1 & .43 & .73 & \\
\hline 1-y follow-up & 3.5 & 1.7 & 4.9 & 2.4 & 3.2 & 1.0 & 5.2 & 1.9 & .30 & .82 & \\
\hline 3-y follow-up & 4.3 & 1.7 & 3.8 & 1.7 & 2.9 & 1.4 & 1.3 & 0.5 & 1.3 & .29 & \\
\hline \multicolumn{12}{|l|}{ Drive for thinness } \\
\hline Pretreatment & 12.1 & 0.9 & 12.8 & 1.0 & 15.3 & 0.7 & 15.4 & 0.6 & 5.2 & .002 & $\mathrm{a}<\mathrm{c}, \mathrm{d}$ \\
\hline 1-y follow-up & 3.8 & 1.0 & 7.1 & 1.5 & 7.5 & 1.3 & 7.4 & 1.1 & 2.3 & .08 & \\
\hline 3-y follow-up & 4.6 & 1.1 & 4.6 & 1.5 & 5.4 & 1.3 & 6.6 & 1.1 & .04 & .60 & \\
\hline \multicolumn{12}{|l|}{ Bulimia } \\
\hline Pretreatment & 9.2 & 0.8 & 8.6 & 1.1 & 10.4 & 0.8 & 9.7 & 0.6 & .79 & .50 & \\
\hline 1-y follow-up & 1.6 & 0.7 & 2.2 & 0.9 & 3.2 & 1.0 & 2.8 & 0.8 & .74 & .53 & \\
\hline 3-y follow-up & 2.4 & 1.3 & 2.4 & 0.9 & 2.0 & 0.9 & 1.8 & 0.6 & .10 & .96 & \\
\hline \multicolumn{12}{|l|}{ Body dissatisfaction } \\
\hline Pretreatment & 15.7 & 1.5 & 15.3 & 1.4 & 20.5 & 1.2 & 21.4 & 1.0 & 6.5 & $<.001$ & $\mathrm{a}, \mathrm{b}<\mathrm{d}$ \\
\hline 1-y follow-up & 8.9 & 1.5 & 9.3 & 1.8 & 11.3 & 1.8 & 14.9 & 1.6 & 3.1 & .03 & \\
\hline 3-y follow-up & 8.0 & 1.6 & 7.3 & 1.1 & 8.8 & 1.7 & 13.1 & 1.7 & 2.6 & .06 & \\
\hline
\end{tabular}

$\mathrm{a}=$ no PD group, $\mathrm{b}=$ personality difficulty group, $\mathrm{c}=$ simple PD group, $\mathrm{d}=$ complex PD group.

${ }^{a}$ Participant numbers for pretreatment were no PD $(n=32)$, personality difficulty $(n=27)$, simple PD $(n=29)$, and complex PD $(n=46)$.

${ }^{b}$ Participant numbers for 1-year follow-up were no PD $(n=27)$, personality difficulty $(n=18)$, simple PD $(n=22)$, and complex PD $(n=34)$.

${ }^{c}$ Participant numbers for 3-year follow-up were no PD $(\mathrm{n}=28)$, personality difficulty $(\mathrm{n}=22)$, simple PD $(\mathrm{n}=24)$, and complex PD $(\mathrm{n}=38)$. The

$P$ values in bold had a statistical significance level of $P<.01$. 
Table 3

General psychiatric functioning and depressive symptomatology at pretreatment and at 1-year and 3-year follow-up

\begin{tabular}{|c|c|c|c|c|c|c|c|c|c|c|c|}
\hline \multirow[t]{2}{*}{$\begin{array}{l}\text { Outcome } \\
\text { measures }\end{array}$} & \multicolumn{2}{|c|}{ No $P^{a}$} & \multicolumn{2}{|c|}{$\begin{array}{l}\text { Personality } \\
\text { difficulty }^{\mathrm{b}}\end{array}$} & \multicolumn{2}{|c|}{ Simple $\mathrm{PD}^{\mathrm{c}}$} & \multicolumn{2}{|c|}{ Complex $\mathrm{PD}^{\mathrm{d}}$} & \multicolumn{3}{|c|}{ Statistics } \\
\hline & $\mathrm{M}$ & $\mathrm{SE}$ & M & $\mathrm{SE}$ & M & $\mathrm{SE}$ & $\mathrm{M}$ & SE & $F$ & $P$ & Post hoc \\
\hline \multicolumn{12}{|l|}{ GAF } \\
\hline Pretreatment $^{\mathrm{a}}$ & 56.1 & 0.8 & 58.0 & 1.3 & 56.9 & 1.1 & 53.1 & 1.2 & 3.9 & .01 & \multirow[t]{3}{*}{$\mathrm{d}<\mathrm{b}$} \\
\hline 1-y follow-up ${ }^{b}$ & 73.8 & 2.2 & 67.6 & 2.6 & 65.9 & 2.4 & 66.1 & 2.4 & 2.5 & .07 & \\
\hline $3-y$ follow-up ${ }^{c}$ & 74.4 & 2.6 & 66.8 & 3.1 & 64.5 & 2.7 & 67.0 & 2.0 & 2.8 & .04 & \\
\hline \multicolumn{12}{|l|}{ HDRS } \\
\hline Pretreatment & 6.0 & 0.9 & 6.1 & 0.8 & 9.7 & 1.0 & 11.1 & 0.8 & 8.3 & $<\mathbf{0 . 0 0 1}$ & \multirow[t]{3}{*}{$\begin{array}{l}a<c, d \\
b<d\end{array}$} \\
\hline 1-y follow-up & 3.0 & 0.6 & 4.8 & 1.0 & 7.0 & 1.4 & 6.1 & 1.3 & 2.2 & .10 & \\
\hline 3-y follow-up & 4.8 & 0.9 & 4.5 & 0.9 & 8.7 & 1.5 & 5.6 & 1.0 & 2.7 & .05 & \\
\hline
\end{tabular}

$\mathrm{a}=$ no $\mathrm{PD}$ group, $\mathrm{b}=$ personality difficulty group, $\mathrm{c}=$ simple $\mathrm{PD}$ group, $\mathrm{d}=$ complex PD group.

a Participant numbers for pretreatment were no PD $(n=32)$, personality difficulty $(n=27)$, simple PD $(n=29)$, and complex PD $(n=46)$.

b Participant numbers for 1-year follow-up were no PD $(n=27)$, personality difficulty $(n=18)$, simple PD $(n=22)$, and complex PD $(n=34)$.

c Participant numbers for 3-year follow-up were no PD $(n=28)$, personality difficulty $(n=22)$, simple PD (n $=24)$, and complex PD (n = 38). The $P$ values in bold had a statistical significance level of $P<.01$.

interaction, $\mathrm{F}_{6,176}=0.4, P=.9$ ) or purge frequency (group $\times$ time interaction, $\left.\mathrm{F}_{6}, 176=0.7, P=.7\right]$. Eating attitudes showed no significant differences in drive for thinness (group $\times$ time interaction, $\mathrm{F}_{6,144}=0.6, P=.7$ ), bulimia (group $\times$ time interaction, $\mathrm{F}_{6}, 144=2.2, P=.05$ ), and body dissatisfaction subscales (group $\times$ time interaction, $\mathrm{F}_{6,144}=$ $0.6, P=.7)$. Similarly, there were no significant difference in changes over time among the groups in general psychosocial functioning (group $\times$ time interaction, $\mathrm{F}_{6,174}=1.5, P=.2$ ) and depressive symptomatology (group $\times$ time interaction, $\mathrm{F}_{6,176}=1.5, P=.2$ ).

\section{Discussion}

This study compared the pretreatment characteristics of women with BN among Tyrer's dimensional personality groups and examined the impact of PD severity on BN outcome at 1 and 3 years posttreatment. There were 3 main findings. First, at pretreatment, individuals with complex PD and $\mathrm{BN}$ showed greater Axis I comorbidity, worse eating attitudes, poorer psychosocial functioning, and more depressive symptoms than the no PD, personality difficulty, and simple PD groups. Despite this, frequency of binge eating and purging was not affected by the presence of complex or simple PDs. Second, BN outcome (ie, eating behaviors, eating attitudes, and diagnosis) showed no significant differences among the groups at 1 year and 3 years posttreatment, indicating that improvement in eating disorder psychopathology after treatment is relatively unaffected by the number of PDs comorbid with BN. Third, although general psychosocial functioning and depressive symptoms were significantly worse in the complex PD and simple PD groups at pretreatment, this was mostly resolved by 1 - and 3year follow-up, with no significant differences found among the 4 groups.
Our findings are consistent with previous studies showing that comorbid $\mathrm{BN}$ and $\mathrm{PDs}$ have greater pathology and poorer general functioning at pretreatment [20,31]. Unlike those studies that reported poorer treatment response, worse outcome, and greater disability associated with complex PD $[9,10,32]$, we found that significant pretreatment differences in eating disorder attitudes (drive for thinness, body dissatisfaction), general psychosocial functioning, and depressive symptoms disappeared in the complex PD group by 1-year follow-up and remained absent at 3-year follow-up.

Although there was a pretreatment difference in eating disorder attitudes in this sample, the absence of differences in eating disorder behaviors (binge eating or purging) in relation to PD severity is consistent with earlier studies reporting that PDs have little impact on the severity of eating behaviors $[14,21,33]$. These results challenge the need for longer psychotherapy or psychotherapy specific to PDs within this population. However, this only pertains to the goal of remission of the eating disorder and not the treatment of the PD. The presence and severity of personality pathology in participants in this psychotherapy trial did not affect their response to relatively brief cognitive behavioral therapy, with the complex PD group indistinguishable at follow-up from the no PD group.

The present study highlights methodological issues in the assessment and interpretation of PD diagnoses. As a result, some consideration should be given to the lack of impact of severe multiple Axis II diagnoses (complex PD) on outcome. Severity and pathology of complex PD may be partly illusory because of the substantial overlap of PD groups [2,34]. This overlap may misrepresent the severity of PDs by increasing the symptoms and diagnoses in the complex PD group, thus implying that they have greater pathology. This issue relates to some of the fundamental problems with the current classification system of PDs and 
may indirectly affect interpretation of findings. A further consideration is that the outcome of BN may not be affected by the presence of any PD regardless of diagnosis or severity. Our results concur with findings from analyses on the same data set that examined the impact of borderline PD and avoidant PD on outcome and found no long-term effect of these personality features on eating disorder symptoms or diagnosis, psychosocial functioning, or depressive symptoms $[23,35]$. This adds to the growing body of research that shows no long-term impact of PDs on the outcome of BN [20,36,37].

This study has several limitations. First is the absence of repeated personality assessments to establish personality status at follow-up given recent evidence of instability of PD diagnoses over time and after treatment [38-40]. The fact that complex PD does not predict outcome in BN may be the result of confounding Axis II diagnosis by acute Axis I distress [41]. Repeated personality assessment would have allowed a clearer understanding of changes in severity and course of the dimensional PD groups over time. Second, reliability data were not available for our outcome measures; however, these raters have conducted interrater reliability checks for Axis I and II diagnosis in an anorexia treatment study and a depression study. The overall $\kappa$ for these ranges from 0.78 to 0.85 , which suggests good concordance for these raters $[42,43]$. Third, the foundation of Tyrer's approach to PDs is based on the validity of current categorical diagnoses and, as such, addresses some but not all of the problems of reliability and stability of personality diagnoses. Finally, although we found that Tyrer's model suggested that severity of personality pathology does not affect outcome in eating disorders, other methods of classifying PD severity need to be examined, for example, total PD symptoms. Although PD severity does not affect the course of an eating disorder, there is still conflicting evidence about whether the nature of the PD may do so $[23,35,44]$. Further replication of this study is needed to establish the validity of Tyrer's dimensional personality classification for those with eating disorders and comorbid Axis II disorders.

To our knowledge, this is the first study to use Tyrer's dimensional personality classification to assess the impact of complex PD on BN outcomes. We can conclude that despite having slightly poorer functioning at pretreatment, participants with BN and comorbid complex PD did not have worse eating disorder or general functioning outcome 1 year and 3 years posttreatment compared with those with less severe personality symptoms (simple PD and personality difficulty) or no personality psychopathology (no PD). Overall, this study suggests that the number of PDs comorbid with BN does not influence the course of an eating disorder. This challenges the idea that treatments such as cognitive behavior therapy need to be adapted for those with comorbid eating disorders and PDs to achieve successful treatment outcomes for an eating disorder.

\section{Acknowledgment}

This study was supported by project and program grants from the Health Research Council of New Zealand and the New Zealand Lottery Grants Board. We thank Leslie Livingston, Isobel Stevens, Robyn Abbott, and Andrea Bartram for their assistance in the coordination of this study.

\section{References}

[1] Morey LC, Hopwood CJ, Gunderson JG, Skodol AE, Shea MT, Yen S, et al. Comparison of alternative models for personality disorders. Psychol Med 2007;37:983-94.

[2] Oldham JM, Skodol AE, Kellman HD, Hyler SE, Rosnick L, Davies M. Diagnosis of DSM-III-R personality disorders by two structured interviews: patterns of comorbidity. Am J Psychiatry 1992;149: 213-20.

[3] Widiger TA, Clark LA. Toward DSM-V and the classification of psychopathology. Psychol Bull 2000;126:946-63.

[4] Livesley WJ, Jang KL. Toward an empirically based classification of personality disorder. J Pers Disord 2000;14:137-51.

[5] Westen D, Shedler J. A prototype matching approach to diagnosing personality disorders: toward DSM-V. J Pers Disord 2000;14: $109-26$.

[6] Widiger TA, Simonsen E. Alternative dimensional models of personality disorder: finding a common ground. J Pers Disord 2005; 19:110-30.

[7] Tyrer P, Johnson T. Establishing the severity of personality disorder. Am J Psychiatry 1996;153:1593-7.

[8] Tyrer P. The problem of severity in the classification of personality disorder. J Pers Disord 2005;19:309-14.

[9] Pulay AJ, Dawson DA, Ruan WJ, Pickering RP, Huang BJ, Chou SP, et al. The relationship of impairment to personality disorder severity among individuals with specific Axis I disorders: results from the national epidemiologic survey on alcohol and related conditions. J Pers Disord 2008;22:405-17.

[10] Tyrer P, Seivewright H, Johnson T. The Nottingham Study of Neurotic Disorder: predictors of 12-year outcome of dysthymic, panic and generalized anxiety disorder. Psychol Med 2004;34:1385-94.

[11] Diaz-Marsa M, Carrasco JL, Saiz J. A study of temperament and personality in anorexia and bulimia nervosa. J Pers Disord 2000;14: $352-9$.

[12] Godt K. Personality disorders in 545 patients with eating disorders. Eur Eat Disord Rev 2008;16:94-9.

[13] Sansone RA, Levitt JL, Sansone LA. The prevalence of personality disorders among those with eating disorders. Eat Disord: J Treat Prev 2005;13:7-22.

[14] Johnson C, Tobin DL, Dennis A. Differences in treatment outcome between borderline and nonborderline bulimics at one-year follow-up. Int J Eat Disord 1990;9:617-27.

[15] Bruce KR, Steiger H. Treatment implications of Axis-II comorbidity in eating disorders. Eat Disord: J Treat Prev 2005;13:93-108.

[16] Chen EY, Matthews L, Allen C, Kuo JR, Linehan MM. Dialectical behavior therapy for clients with binge-eating disorder or bulimia nervosa and borderline personality disorder. Int J Eat Disord 2008;41 (6):505-12.

[17] Fairburn CG, Cooper Z, Doll HA, O'Connor ME, Bohn K, Hawker $\mathrm{DM}$, et al. Transdiagnostic cognitive-behavioral therapy for patients with eating disorders: a two-site trial with 60-week follow-up. Am J Psychiatry 2009;166:311-9.

[18] Fairburn CG. Interpersonal psychotheraphy for bulimia nervosa. In: Garner DM, Garfinkel PE, editors. Handbook of treatment for eating disorders. 2nd ed. New York: Guilford; 1997. p. 278-94. 
[19] Picot AK, Lilenfeld LR. The relationship among binge severity, personality psychopathology, and body mass index. Int J Eat Disord 2003;34:98-107.

[20] Wonderlich SA, Fullerton D, Swift WJ, Klein MH. 5-Year outcome from eating disorders: relevance of personality disorders. Int J Eat Disord 1994;15:233-43.

[21] Bulik CM, Sullivan PF, Joyce PR, Carter FA, McIntosh VV. Predictors of 1-year treatment outcome in bulimia nervosa. Compr Psychiatry 1998;39:206-14.

[22] Grilo CM, Pagano ME, Skodol AE, Sanislow CA, McGlashan T, Gunderson J, et al. Natural course of bulimia nervosa and of eating disorder not otherwise specified: 5-year prospective study of remissions, relapses, and the effects of personality disorder psychopathology. J Clin Psychiatry 2007;68:738-46.

[23] Rowe SL, Jordan J, McIntosh V, Carter FA, Bulik CM, Joyce PR. Impact of borderline personality disorder on bulimia nervosa. Aust $\mathrm{N} \mathrm{Z}$ J Psychiatry 2008;42:1021-9.

[24 Bulik CM, Sullivan PF, Carter FA, McIntosh VV, Joyce PR. The role of exposure with response prevention in the cognitive-behavioural therapy for bulimia nervosa. Psychol Med 1998;28:611-23.

[25] Carter FA, McIntosh VVW, Joyce PR, Sullivan PF, Bulik CM. Role of exposure with response prevention in cognitive-behavioral therapy for bulimia nervosa: three-year follow-up results. Int J Eat Disord 2003;33: 127-35.

[26] Spitzer RL, Williams JB, Gibbon M, First M. Structured clinical interview for DSM-III-R: patient version. Washington D.C.: American Psychiatric Press, Inc; 1990

[27] Sullivan PF. The comprehensive bulimia structured interview. Unpublished manuscript. Christchurch: Christchurch School of Medicine, University of Otago; 1993.

[28] Fairburn CG, Cooper Z. The eating disorders examination. In: Fairburn CG, Wilson GT, editors. Binge-eating: nature, assessment and treatment. 12th ed. New York: Guilford Press; 1993. p. 317-60.

[29] Hamilton M. A rating scale for measuring depression. J Neurol Neurosurg Psychiatry 1960;23:56-62.

[30] Garner DM, Olmsted MP, Polivy J, Darby PL, editors. The Eating Disorders Inventory: a measure of cognitive-behavioural dimensions of anorexia and bulimia. Anorexia nervosa: recent developments in research New York; 1983. p. 173-84.

[31] Steiger H, Stotland S. Prospective study of outcome in bulimics as a function of Axis-II comorbidity: long-term responses on eating and psychiatric symptoms. Int J Eat Disord 1996;20:149-61.
[32] Moran P, Walsh E, Tyrer P, Burns T, Creed F, Fahy T. Impact of comorbid personality disorder on violence in psychosis - Report from the UK700 trial. Br J Psychiatry 2003;182:129-34.

[33] Steiger H, Thibaudeau J, Leung F, Houle L, Ghadirian AM. Eating and psychiatric symptoms as a function of Axis-II comorbidity in bulimic patients: 3-month and 6-month responses after therapy. Psychosomatics 1994;35:41-9.

[34] Fossati A, Maffei C, Bagnato M, Battaglia M, Donati D, Donini M, et al. Patterns of covariation of DSM-IV personality disorders in a mixed psychiatric sample. Compr Psychiatry 2000;41:206-15.

[35] Rowe SL, Jordan J, McIntosh VV, Carter FA, Frampton C, Bulik CM, Joyce PR. Does avoidant personality disorder impact on the outcome of treatment for bulimia nervosa? Int J Eat Disord [In Press].

[36] Fallon BA, Walsh BT, Sadik C, Saoud JB, Lukasik V. Outcome and clinical course in inpatient bulimic women: a 2-year to 9-year followup study. J Clin Psychiatry 1991;52:272-8.

[37] Grilo CM, Sanislow CA, Shea MT, Skodol AE, Stout RL, Pagano ME, et al. The natural course of bulimia nervosa and eating disorder not otherwise specified is not influenced by personality disorders. Int J Eat Disord 2003;34:319-30.

[38] Grilo CM, McGlashan TH, Skodol AE. Stability and course of personality disorders: the need to consider comorbidities and continuities between axis I psychiatric disorders and axis II personality disorders. Psychiatr Q 2000;71:291-307.

[39] Lenzenweger MF, Johnson MD, Willett JB. Individual growth curve analysis illuminates stability and change in personality disorder features: the longitudinal study of personality disorders. Arch Gen Psychiatry 2004;61:1015-24.

[40] Tyrer P, Seivewright H. Stable instability: the natural history of personality disorders. Psychiatry 2008;7:129-32.

[41] Vitousek KM, Stumpf RE. Difficulties in the assessment of personality traits and disorders in eating-disordered individuals. Eat Disord: J Treat Prev 2005;13:37-60.

[42] Carter JD, Joyce PR, Mulder RT, Sullivan PF, Luty SE. Gender differences in the frequency of personality disorders in depressed outpatients. J Pers Disord 1999;13:67-74.

[43] Jordan J, Joyce PR, Carter FA, Horn J, McIntosh VVW, Luty SE, et al. Specific and nonspecific comorbidity in anorexia nervosa. Int $\mathrm{J}$ Eat Disord 2008 Jan;41:47-56

[44] Thompson-Brenner H, Eddy KT, Franko DL, Dorer DJ, Vashchenko M, Kass AE, et al. A personality classification system for eating disorders: a longitudinal study. Compr Psychiatry 2008;49:551-60. 